\title{
ДОСЛІДЖЕННЯ ОПОРУ ВИТЯГАННЯ АРМАТУРНИХ СТЕРЖНІВ 3 БЕТОНІВ РІЗНИХ КЛАСІВ
}

\section{RESEARCH OF THE RESISTANCE OF PULLING OUT STEEL BARS FROM CONCRETES OF DIFFERENT CLASSES}

\author{
Філіпчук С.В. к.т.н., доц., Поляновська О.С., к.т.н, \\ (Національний університет водного господарства та \\ природокористування, м. Рівне),
}

Filipchuk S.V. Ph.D. in Engineering, Associate Professor, Polianovska O. Ye. Ph.D. in Engineering, Associate Professor, (National University of Water Management and Nature Resources Use, Rivne)

Наведені результати експериментальних досліджень зчеплення арматури 3 бетонами різних класів. Проведений аналіз впливу довжини анкетування та діаметра арматури на граничні напруження зчеплення арматури з бетоном.

The article gives the results of the experimental researches of the bond between steel and concretes of different classes. The basic test samples were produced in the form of concrete prisms of square cross section, sides of which equal $15 \mathrm{~cm}$, and the height corresponds to the planned length of anchorage. Steel bars were located in the prisms in such a way that their longitudinal axis matched together, and parts of bars cantilevering out of prisms allowed to fasten in the grip of the hydraulic press on the one side, and on the other (free) side of the bars to measure their displacement relative to the end of the prisms. The analysis of the impact of the concrete cover on the boundary stresses of the bond between steel and concrete was carried out. The analysis of regression equation structures shows the absence of the linier impact of the bar diameter on the boundary stresses of the bond $f_{b}$. The obtained mathematical model allows analyzing the impact of factors, that were investigated on the boundary stresses on the contact surface of steel and concrete. The analysis of the results of the experimental researches speaks that the depth of the concrete cover has a significant impact on the boundary bond stresses. A similar relative reduction of the bond stresses is observed in samples with steel bars of 16 i $20 \mathrm{~mm}$ in diameter. 
Thus, the maximum bond occurs at the largest concrete cover, while the minimum bond being at the least. The character of destruction of the samples also depends on the depth of the concrete cover. At $c=3 d$ the destruction occurred in three-four planes with the appearing of cracks on the lateral area, the prism was divided into separate elements. However, in the prisms with the concrete cover $l_{b}=10 d$ there was a stiffening of the steel bar and appearance of a split in the direction toward all sides. At $c=1,5 d$ cracks were developed within the concrete cover, but immediately before the complete destruction - in the direction toward the cheeks. In the samples with $c=1 d$, the destruction took place in the plane which crossed the concrete cover. It should be noted that the longitudinal cracks were formed along the longitudinal actions of the bars as a result of the wedging moment of the transverse actions, located at the angle to the direction of pulling out the bars. It has been experimentally proved that the depth of the concrete cover substantially affects the maximum stresses of the bond between concrete and steel and the character of destructing prisms.

Ключові слова: міцність, арматура, бетон, зчеплення.

Keywords: strength, armature, concrete, adhesion.

Вступ. Зчеплення арматури 3 бетоном $є$ важливою якістю залізобетону, яка визначає його несучу здатність, жорсткість та тріщиностійкість, залежить від великої кількості факторів: міцності бетону, виду і діаметра арматури, довжини зароблення стержнів у бетон, товщини захисного шару бетону, характеру навантаження, тривалих процесів, гранулометричного складу суміші, природи наповнювачів, умов твердіння, розташування стержнів при бетонуванні тощо [1]. В зв'язку 3 цим надійність анкерування арматури в залізобетонних конструкціях також залежить від численних факторів, які визначають іiі зчеплення з бетоном. Із-за великої кількості впливових факторів задача вивчення зчеплення арматури з бетоном складна, але дуже актуальна [2].

Бетон відноситься до числа погано організованих або так званих дифузних систем, характерними рисами яких $\epsilon$ неможливість чіткого виділення окремих явищ i необхідність урахування багатьох різнорідних факторів. Стосовно зчеплення арматури 3 бетоном систему «бетон - арматура» також можна розглядати як дифузну систему. Для дифузних систем в умовах 
неповного знання механізму всього явища зчеплення особливо ефективним є статистичний і кібернетичний методи дослідження. Перший дозволяє розробляти рекомендації з оптимальної поведінки системи в умовах невизначеності, а також представляти експериментальний матеріал у формі аналітичного виразу рівняння регресії.

Методика досліджень. В дослідженнях виконано три серії трьох факторних експериментів. В кожній точці плану виготовляли по три зразки - близнюки, а на основному рівні - шість зразків. Основні дослідні зразки виготовляли у вигляді бетонних призм квадратного перерізу, сторони якого дорівнювали 15 см, а висота запланованій довжині анкетування (рис. 1). Формування зразків здійснювали в дерев'яних формах, в які попередньо встановлювалися арматурні стержні. Арматурні стержні розташовували в призмах таким чином, щоб їхні поздовжні осі співпадали, а виступаючі 3 призм частини стержнів дозволяли 3 одного боку закріплювати в захватах гідравлічного преса, а 3 другого (вільного) кінця стержнів - вимірювати їхні переміщення відносно торця призм (рис. 2).

Також поряд 3 основними зразками виготовлялися кубики розміром $150 \times 150 \times 150$ мм для визначення кубикової міцності бетону у віці 28 діб і в період випробувань зразків, призми розміром $150 \times 150 \times 600$ мм для визначення призмової міцності бетону й початкового модуля пружності у віці 28 діб та під час випробувань зразків.

В дослідах використовували арматуру класу А500С діаметром 12, 16 та 20 мм, яка найбільш поширено використовується для армування залізобетонних конструкцій.

Для виготовлення зразків використовувався бетон класів C16/20, С20/25, С25/30 та С60/70. У віці 28 діб середня кубикова міцність для бетонів класів С16/20, С20/25, С25/30 і С60/70 склала відповідно $f_{\text {cm, cube }}=24,6 ; 29,7 ; 34,7$ та 70,4 МПа. Згідно з ДБН В.2.698:2009 така кубикова міцність практично відповідає названим класам бетону $[3,4]$. 


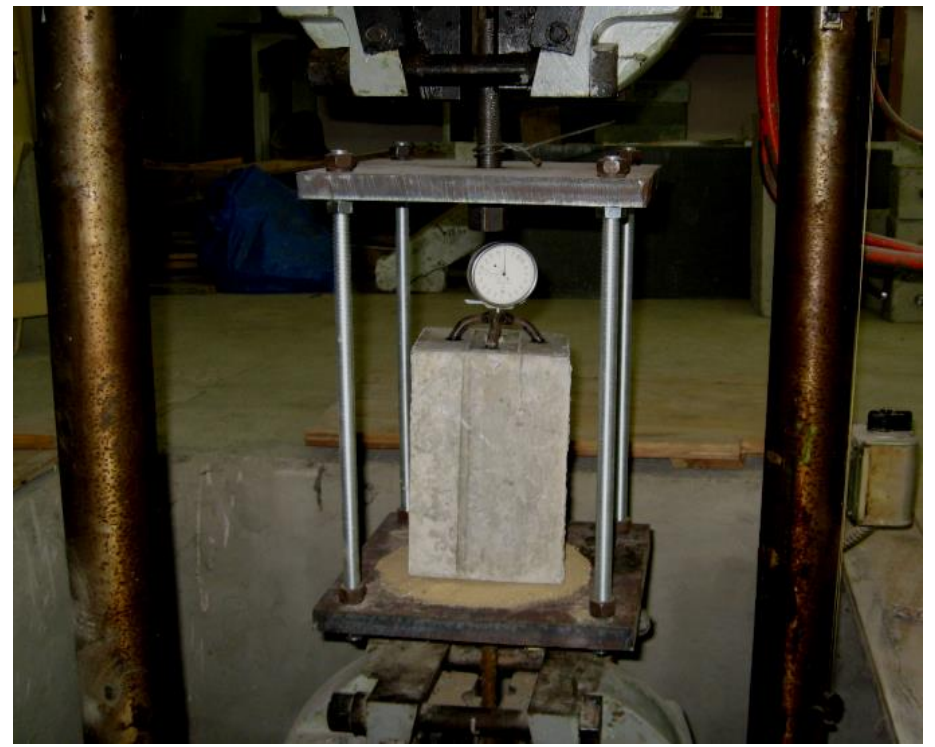

Рис 1. Загальний вигляд випробування зразків

Дослідження зчеплення арматури 3 бетоном здійснювали шляхом витягування стержнів із бетонних призм з використанням спеціального реверсного пристрою в розривній гідравлічній машині УИМ-50. Витягування стержнів виконували ступенями, рівними $\Delta F$ $=(0,5 \ldots 1,0) \kappa \mathrm{H}$

За граничний стан зчеплення арматури 3 бетоном приймали зусилля в стержні $F_{u}$, коли зміщення його вільного кінця відносно торця призми складало $\delta_{u}=0,1$ мм або відбувалося розколювання призми при $\delta<0,1$ мм.

В граничному стані визначалися максимальні середні по довжині дотичні напруження (напруження зчеплення) для кожного зразка за формулою

$$
f_{b i}=F_{u i} /\left(\pi \cdot d \cdot l_{b}\right),
$$

де $f_{b i}$ - граничні середні по довжині напруження зчеплення $i$-го зразка по поверхні контакту стержня з бетоном;

$F_{u i}$ - руйнуюче зусилля $i$-го зразка в граничному стані;

$d$ - діаметр стержня;

$l_{b}$ - довжина заробки стержня в бетон (довжина анкерування стержня). 

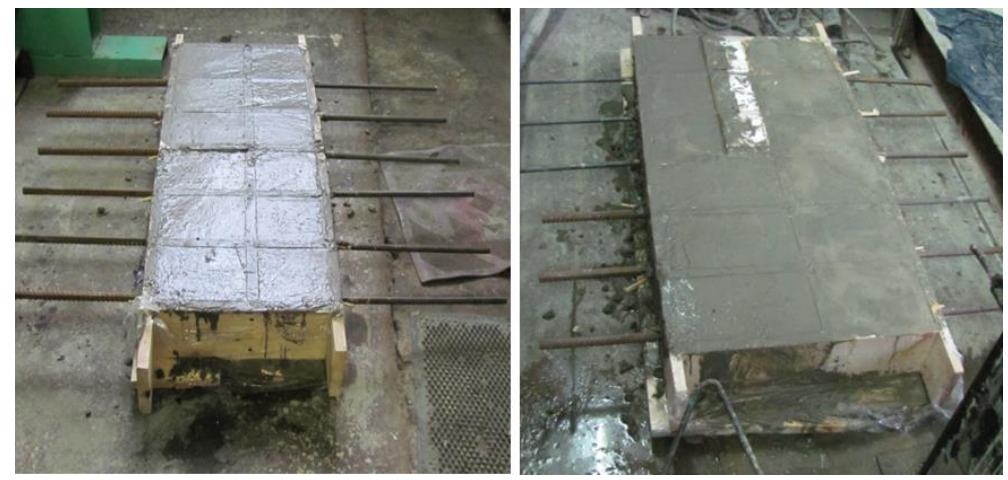

Рис. 2. Виготовлення основних зразків в касетних дерев'яних формах

Граничні середні дотичні напруження, які виникають на поверхні контакту стержня 3 бетоном $f_{b}$, що визначалися за формулою (1), можна називати міцністю зчеплення арматури 3 бетоном. Критерієм міцності є зміщення торця стержня в бетоні на 0,1 мм і більше або розколювання бетону.

Результати досліджень. Розглянемо характер напружень зчеплення для бетонів звичайних класів С16/20, С20/25 і C25/30. При довжині анкерування $l_{b}=5 d$ для діаметрів стержнів $d=12,16 \mathrm{i}$ 20 мм міцність бетону практично лінійно впливає на напруження $f_{b}$, а для стержнів діаметром $d=25$ - цей вплив стає криволінійним, при цьому зі збільшенням міцності бетону за межами плану експерименту значення $f_{b}$ зменшуються. Так для зразків з діаметром 12 мм при $f_{c m, p r i s m}=26,1$ МПа граничний стан настав, коли $f_{b}=6,82$ МПа, а при діаметрі стержнів 20 і 25 мм розрахункове значення напружень зчеплення відповідно склало $f_{b}=6,52$ і 3,99 МПа. Зіставляючи ці розрахункові значення 3 експериментальними даними, можна прийти до висновку, що довжину анкерування, рівною $l_{b}=5 d$, не слід використовувати при конструюванні залізобетонних елементів. Крім цього, при такій довжині анкерування значно не використовується міцність арматури (рис 3). 

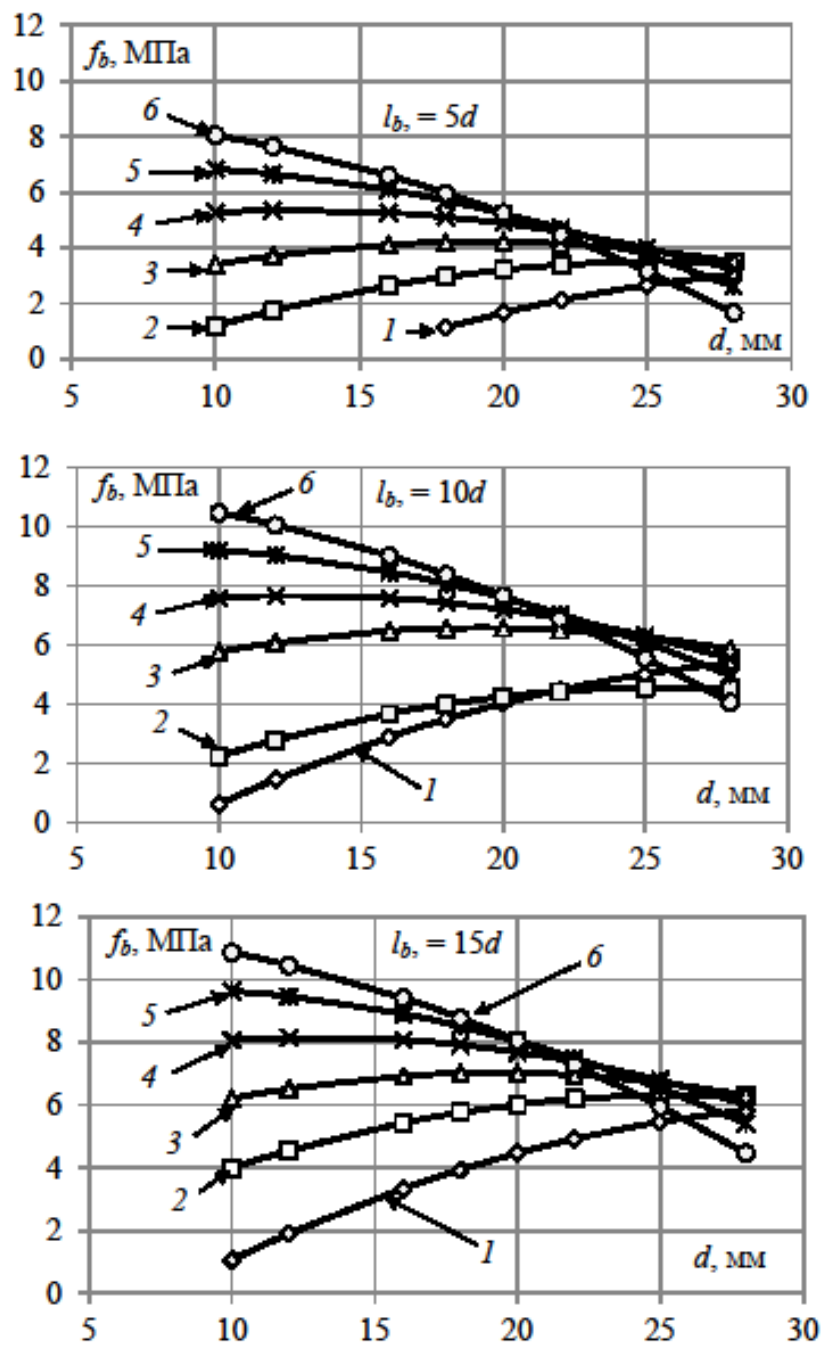

1 - клас бетону $12 / 15 ; 2$ - те саме - 16/20; 3 - те саме -20/25; 4 - те саме - 25/30; 4 - те саме ; 5 - те саме - 30/35; 6 - те саме $35 / 40$

Рис. 3. Вплив діаметра стержнів на граничні напруження зчеплення по поверхні контакту з бетоном 
У нормах проектування залізобетонних конструкцій мінімальне значення заведення стержнів в бетон за внутрішню грань вільної опори рекомендується приймати рівним $l_{b}=10 d$. За такого значення $l_{b}$ для стержнів діаметром 12 мм 3 підвищенням класу бетону 3 $\mathrm{C} 16 / 20$ до $\mathrm{C} 35 / 40$, тобто, в 1,93 рази, граничні напруження зчеплення збільшилися $3 f_{b}=4,61$ до $f_{b}=10,43$ МПа, тобто, в 2,26 рази. При підвищенні класу бетону до С60/70, тобто, в 2,86 рази порівняно с бетоном класу C16/20, граничні напруження зчеплення збільшилися до $f_{b}=12,17$ МПа, тобто, в 2,64 рази. Проаналізувавши дані значення можна зробити висновок, що зі збільшенням класу бетону відбувається і збільшення зчеплення, проте 3 меншим приростом, ніж для менших класів бетону (рис. 4).

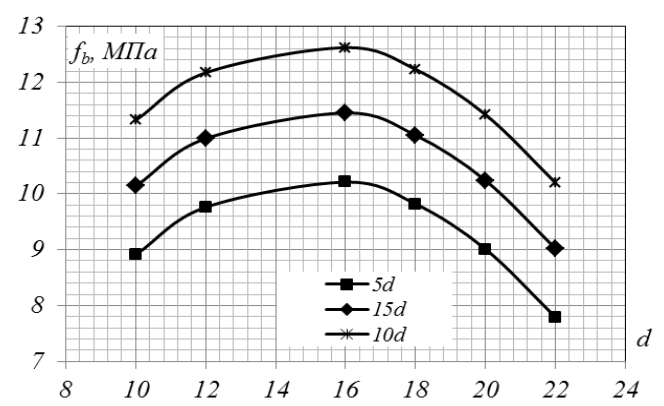

Рис. 4. Вплив діаметра стержнів на граничні напруження зчеплення по поверхні контакту з бетоном класу C60/70

Приблизно такий характер залежності має місце і для стержнів діаметром 16 і 18 мм, але для стержнів діаметром 20 мм і більше збільшення $f_{b}$ значно менше.

При довжині анкерування $l_{b}=15 d$ для всіх класів бетонів граничні напруження зчеплення мали проміжні значення між $l_{b}=5 d$ та $l_{b}=10 d$.

Характер руйнування зразків також залежить від товщини захисного шару (рис. 5). При $c=3 d$ руйнування відбувалося по трьом - чотирьом площинах 3 виходом тріщин на бокові поверхні, призма розділялася на окремі елементи. Проте в призмах із захисним шаром $l_{b}=10 d$ спостерігалося висмикування стержня 3 утворенням поздовжніх тріщин в напрямку до всіх граней. При $c=$ $1,5 d$ тріщини розвивалися в межах захисного шару, а безпосередньо 
перед повним руйнуванням - в напрямку до бічних граней. В зразках, в яких $c=1 d$, руйнування відбувалося по площині, яка перетинала захисний шар. Треба зазначити, що поздовжні тріщини утворювалися вздовж поздовжніх виступів стержнів, внаслідок розклинювальної дії поперечних виступів, які розташовані під кутом до напрямку витягування стержнів.
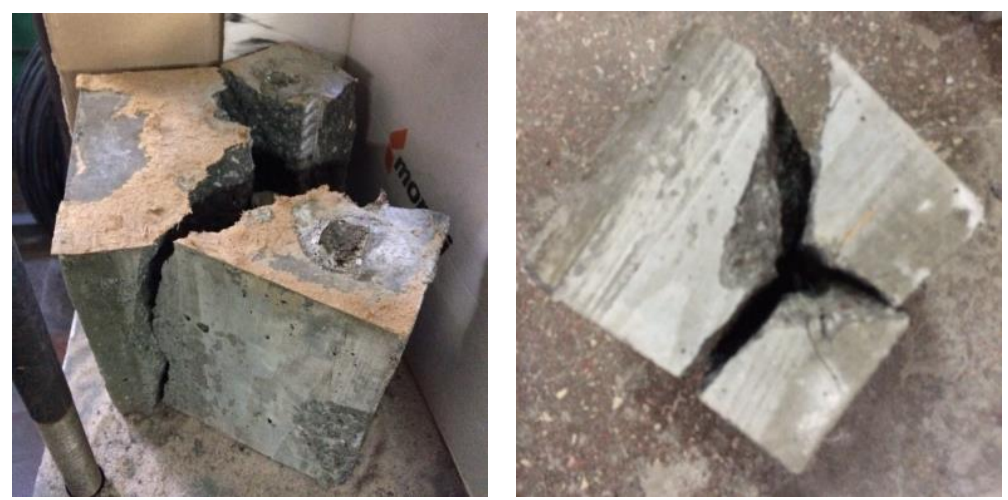

Рис. 5. Характер руйнування зразків 3 діаметром стержнів 16 мм

Висновок. Зі збільшенням класу бетону відбувається i збільшення зчеплення, проте з меншим приростом ніж для менших класів бетону. Товщина захисного шару впливає на характер руйнування призм.

1. Зчеплення з бетоном арматури серпоподібного профілю та іï анкерування в згинальних залізобетонних елементах: Монографія / Є. М. Бабич, В. Є. Бабич, О. Є. Поляновська .- Рівне: «Волинські обереги», 2017. - 160 c. 2. Babych, Y., Filipchuk, S., Fenko, O., "Mathematical modeling of the resistance of pulling out steel bars from high strength concrete,"International Journal of Engineering and Technology (UAE), vol. 7 (3.2), pp. 516-521, May 2018. 3. Дворкін Л.Й., Бабич Є.М., Житковський В.В., Бордюженко О.М., Філіпчук С.В.,Кочкарьов Д.В., Ковалик І.В., Ковальчук Т.В., Скрипник М.М. Високоміцні швидкотверднучі бетони та фібро бетони - Рівне: НУВГП, 2017. 331 с. 4. Механічні характеристики швидкотверднучих високоміцних бетонів. / С.М. Бабич, В.С. Бабич, С.В. Філіпчук, Д.В. Кочкарьов // Ресурсоекономні матеріали, конструкції, будівлі та споруди: Збірник наукових праць. - Рівне: НУВГП, 2016. - Випуск 32. - С. 114 120. 